\title{
EL FORO PENAL Y EL SISTEMA DE PENAS
}

\author{
Alfredo Etcheberry \\ Profesor de Derecho Penal \\ Universidad de Chile
}

Estimados colegas y amigos:

Mi intervención debe comenzar por un doble agradecimiento. En primer término, por la honrosa invitación que se me formuló para intervenir en este Seminario, y que he aceptado gustosamente. Ha llegado a nuestro conocimiento por muchas vías la labor ejemplar que esta casa de estudios realiza, y particularmente la atención que ha dedicado a la estructura teórica y a la aplicación práctica de la reforma procesal penal, que ha cobrado vida en esta Región junto con la Novena, y cuya experiencia será la que marque rumbos en una nueva realidad. Todos los que estamos vitalmente comprometidos con este ámbito en que se entrecruzan leyes y hombres, estamos pendientes de su éxito, y agradecemos a los hombres y mujeres del mundo académico local los serios y nobles esfuerzos con que contribuyen al buen resultado del nuevo sistema. $Y$ en segundo lugar, por las palabras tan amables y afectuosas con que he sido recibido, que ciertamente no me corresponden y que son más bien hijas del afecto con que he sido siempre recibido aquí.

En particular, me es especialmente grato dejar testimonio de la estrecha vinculación que este Seminario ha tenido con el Foro Penal. Tanto el profesor Jean Pierre Matus, que hoy me acompaña y a quien acabamos de escuchar, como el que les habla, somos miembros activos del Foro, y Héctor Hernández, a quien ustedes escucharon ayer, es el verdadero motor jurídico que está detrás del Foro: nos hace el trabajo de preparación y de síntesis de las sesiones y creo que si la labor del Foro llega a buen término, se deberá en gran parte a sus esfuerzos.

Por esa razón a cualquiera de ustedes que haya estado participando en el Foro, le pido excusas si repito conceptos que ya conocen o que ya se han dicho, pero me parece más interesante discutir de los sistemas penitenciarios en abstracto como podía haberse hecho, exponer lo que se está pensando o lo que se ha dicho sobre los sistemas penitenciarios en este Foro Penal. Para eso, hay que comenzar por hablar un poco de lo que es el Foro mismo, la manera como se desarrolla y cuáles son sus propósitos. En la sesión en la cual se inauguró el Foro Penal con asistencia del Ministro de Justicia, y del Presidente de la Corte Suprema me correspondió, en mi calidad de coordinador, recordar que cuando el año 1975 se celebraron las jornadas para conmemorar el centenario de la entrada en vigencia de nuestro Código Penal, se publicó una edición de 
las actas de la Comisión Redactora del Código y el texto original aprobado por esa Comisión con un estudio, obra del profesor, don Manuel de Rivacoba, que decía textuaimente "... desaparecido en 1973 el vetusto Código Penal Boliviano de 1834, el chileno es hoy el más antiguo del continente americano y uno de los más antiguos del mundo. En lengua castellana, sólo le sobrepasa el Español, en otros idiomas el Francés, el Haitiano, el Austriaco, el Belga, el Alemán y el de San Marino. Se apresta ( hace 25 años) a cumplir un siglo...", y el profesor Rivacoba hacía alusión al Código Español porque consideraba, y con toda razón, que "El" Código Español era aquél en que se inspiró el nuestro, el año 1848, y aunque los españoles hayan dado el nombre de Código del año '70, Código del año '32, etc. a las sucesivas modificaciones. En realidad básicamente eran el mismo código, el Código de Pacheco.

Veinticinco años más tarde, podemos decir que nuestro país, donde no abundan mucho los récords mundiales de cualquiera naturaleza, ya ha alcanzado uno, y si no lo ha alcanzado está muy próximo. En efecto, dentro de la lengua castellana ya el año '95 España se dio un nuevo Código Penal, y de los que nombró el profesor Rivacoba en esa oportunidad, también promulgaron nuevos códigos penales en estos últimos veinticinco años Austria, Alemania y Francia. Somos uno de los pocos países que conserva un Código Penal promulgado en el siglo XIX, y otro rasgo que nos singulariza, por lo menos entre los países de habla castellana, es que es el único Código Penal que hemos tenido en nuestra existencia republicana. Tanto España, la madre patria, como las repúblicas sudamericanas, se han dado sucesivos y numerosos Códigos Penales. Esta situación sin embargo no ha transcurrido pacíficamente todo el tiempo. La inquietud por reemplazar el Código Penal se hizo sentir con particular fuerza entre nosotros en la primera mitad del Siglo XX. Conservamos de ella los proyectos de 1929 que fueron dos, el Proyecto de Pedro Ortiz y Ludwing von Bohlen, que es de corte dogmático jurídico, antes de que esa denominación estuviera en uso, y el de Erazo y Fontecilla, de mayor influencia positivista, aunque Fontecilla, ilustre jurisconsulto y brillante magistrado que llegó a presidir nuestra Corte Suprema, y que fue el primero entre nosotros que escribió sobre "el concurso aparente de leyes", evolucionó después personalmente hacia una postura menos positivista y más de corte dogmático, inspirado en la doctrina alemana.

En 1938, por iniciativa puramente privada de sus autores, el proyecto de Pedro Silva Frenández y Gustavo Labatut, de corte marcadamente ecléctico, no doctrinal, introdujo sin embargo novedades de importancia como la reglamentación de las medidas de seguridad, que hasta entonces no habian sido reguladas en Chile, y el establecimiento de la responsabilidad penal de las personas jurídicas, con determinadas modalidades. En fin, existió también el Proyecto de 1946, obra de una comisión en la que estuvieron representados los más ilustres jurisconsultos de la época, que ya muestra un sesgo marcadamente dogmático-jurídico, superada afortunadamente la absurda y la estéril llamada "lucha de las escuelas" clásica o positiva, que tanto daño 
hizo y tanto retraso provocó en la necesaria evolución de la Ley Penal. Este proyecto del año '46, desgraciadamente no alcanzó siquiera a ser terminado y menos por cierto a ser sometido a consideración legislativa.

Sin entrar en las características y contenidos de cada uno de estos intentos, merece destacarse el rasgo muy realista y positivo de que en la redacción de cada uno de ellos intervinieron por igual personas que desempeñaban la cátedra y personas que desempeñaban la magistratura, a veces en alianza intelectual, y a veces, como en el caso de Pedro Ortiz, encarnadas ambas calidades en las mismas personas. Eso muestra una muy saludable alianza entre la teoría y la práctica, y el convencimiento, que decididamente compartimos, de que las reglas que deben regir la conducta de los hombres en sociedad, para que vivan en paz y con justicia, no deben elaborarse solamente en los paraísos académicos. Sigue teniendo valor la advertencia formulada ya hace tiempo por CARNEVALE "estudiar en los gabinetes, discutir en la escuela, avanzar hipótesis, modificarlas y retirarlas, ponerse de acuerdo o polemizar, es una cosa: hacer experimentos sobre la libertad de los ciudadanos es otra cosa".

No debe olvidarse en estos intentos de reforma de legislación penal, la iniciativa del instituto de Ciencias Penales de Chile, entonces bajo la presidencia del profesor Novoa Monreal, para la elaboración de un Código Penal "Tipo o Modelo" para Iberoamérica, ambicioso proyecto que sin embargo alcanzó un éxito insospechado, pese a las naturales dificultades de su elaboración, porque se hizo con el trabajo de numerosas comisiones en paralelo en países distintos, cuando incluso los sistemas de comunicación inmediata, que facilitan tanto el trabajo hoy día, no existían y que en su mejor é poca, entre los años 1963 y 1973, logró dar término completo a un Proyecto de Parte General y en medida apreciable, de la Parte Especial. Los preceptos de ese proyecto, destinado a servir de modelo a todos los países iberoamericanos, alcanzaron incluso consagración legislativa en Costa Rica.

La supervivencia de nuestro Código por lo que son ya 126 años, no es a mi juicio en sí misma evidencia, ni de la necesidad urgente de reemplazarlo por otro por su obsolescencia, ni tampoco de sus virtudes, que le hayan permitido sobrevivir sin que la sociedad en que ha regido, básicamente, democrática y liberal, lo haya sentido como arcaico o insoportable.

Señalaremos solamente una desventaja y una ventaja que este Código tan antiguo muestra a nuestro juicio. La desventaja, por llamarla así, consiste en que el Código ha perdido toda pretensión de conservar lo que es propio de un Código, la esencia de la codificación: la concentración en sí y el práctico monopolio del elenco de ilícitos penales. La idea que presidió la codificación modelada por la Escuela de la Exé gesis en los grandes Códigos Napoleónicos era ésa: que en vez de tanta ley dispersa y difícil de encontrar por la mezcla de autores, de precedentes legislativos, de 
jurisprudencia, etc. que hacía muy difícil saber lo que fuera el derecho, se reemplazara por un solo libro: el Código. Y además, claro, fácil de entender y que junto con la Biblia y el Diccionario, formará parte del hogar de cada persona, sin necesidad de tener que andar preguntando cuál era el derecho vigente o cuáles eran los derechos de cada uno.

Hay leyes numerosísimas, importantes, que ustedes conocen de sobra, que establecen delitos y penas, sobre las más variadas materias y de muy distinta clase, que no forman parte del Código, y probablemente desde el punto de vista estadístico, el trabajo de los Tribunales de Crimen en la actualidad, recae sobre delitos que no están contemplados en el Código Penal sino en otras leyes.

La ventaja, por otro lado, es que esta proliferación legislativa penal ha tomado básicamente el camino de crear nuevos delitos concretos y específicos, pero no ha pretendido innovar en lo que llamamos la Parte General del Código y sus principios que son esencialmente liberales: que no hay delito sin pena, que esta ley debe ser previa, que no hay delito sin culpa, cuáles son los elementos del delito, las causales que eximen de responsabilidad penal, quiénes tienen el carácter de responsables, cuales son las atenuantes y agravantes, las normas para tratar los concursos de delitos, las etapas de desarrollo del delito, las reglas para la determinación de la pena y la extinción de la responsabilidad penal.

Esta vigencia permanente de todo este conjunto, ha sido el ancla más eficaz para conservar el carácter garantista y liberal de la ley penal, y liberarla de las veleidades como el estado peligroso, la responsabilidad objetiva y otros principios que con el pretexto de la defensa social, sacrifican los derechos esenciales de la persona. Sin embargo, una luz de advertencia nos indica que ha llegado la hora de examinar más a fondo la totalidad de las disposiciones del Código. Me refiero a la facilidad y la desenvoltura, francamente irresponsable, con que en los últimos tiempos se ha modificado múltiples veces el Código, no como fruto de una sabia reflexión, sino bajo el impulso emocional del delito más fresco en los medios de comunicación y el deseo de alcanzar aprobación en las llamadas encuestas de opinión pública. Esto indica, o que se ha perdido todo respeto por el Código, o que la sociedad ya no profesa los valores humanos y liberales que lo inspiraron.

Para ese examen tranquilo, serio, profundo, se creó el Foro. Para explicarles a ustedes con precisión qué es esto del Foro, diremos primero: nos hemos constituido en un Foro, no en una comisión. Una comisión, como su nombre lo indica tiene un "encargo": se le ha cometido una tarea, debe llevarla a cabo y debe rendir cuenta de lo que hizo, y para poder progresar, si hay puntos en que se producen discrepancias insalvables entre sus miembros, tiene necesariamente que producir votaciones, y decir el parecer de la mayoría de la comisión fue tal... etc. Un Foro no es eso. El Foro sólo recibe con la mayor amplitud posible todas las voces y las opiniones, provoca un 
diálogo enriquecedor y deja testimonio de todos los pareceres, sin pretender forzarlos ni someterlos al escrutinio de mayorías o minorías, ni al acuerdo forzado sobre la base de un compromiso, porque estamos empantanados y no hallamos cómo salir: entonces vamos a buscar una solución intermedia o ecléctica. No, el Foro recibe y consigna todas las opiniones, nadie sabe si cuando la labor del Foro termine, esas opiniones, que tal vez fueron minoritarias en el Foro, sean tomadas en consideración para lo que puede ser un proyecto de redacción de un Código íntegramente renovado. Nuestra misión, por este mismo motivo, no es la de redactar un Código nuevo, sino la de reexaminar críticamente el Código en vigencia. Si la amplitud y la profundidad de las críticas, o la dimensión de las reformas aconsejadas muestran como deseable la elaboración de todo un código nuevo, (no creo ser indiscreto si les digo que la mayor parte de los que estamos en el Foro creemos que asi va a ser) así se propondrá a quienes tienen la autoridad política, al poder ejecutivo y al poder legislativo, para convertir las ideas en leyes, pero no nos corresponderá a nosotros mismos hacer ese texto, a menos que la misma autoridad con el tiempo nos encomiende además esa tarea al Foro completo o a una comisión más reducida.

Para pertenecer al Foro no se ha puesto ningún requisito indispensable: pueden concurrir a él los magistrados, los catedráticos, los abogados que ejercen en lo penal, y en general, cualquiera que manifieste su interés y su deseo de incorporarse a sus trabajos, puede así manifestarlo a la Secretaría del Foro y pasará a ser invitado a formar parte de él. Y por eso mismo el que les habla, no tiene la función ni el título de Presidente del Foro, sino de Coordinador General, cuya tarea es estar atento a tantas voces valiosas y consignarlas todas, regular la marcha de las sesiones y las reflexiones de nuestro Foro y finalmente sintetizar los pareceres ya decantados o delimitados por el debate,

El Foro, a mi parecer, ha tenido presentes las recomendaciones hechas en el decreto de nombramiento en 1846 de cuatro ilustres juristas para la redacción de sendos Códigos: Penal y de Procedimiento Penal, tarea que desafortunadamente no pudieron llevar a cabo por la brevedad del plazo que se les otorgó. En el decreto de nombramiento se les dice textualmente que "deberán prestar especial atención a los delitos que son más frecuentes en Chile, pero sin pretender extirparlos por una desproporcionada severidad en las penas, y economizando la Pena de Muerte (ya suprimida hoy) deberán dispensar más lenidad a los delitos que nacen de ignorancia o sumisión y que más que un ánimo depravado evidencian inexperiencia y debilidad". Esa es una instrucción que a mi juicio ha venido inspirando los debates del Foro.

El Foro se reúne ordinariamente, con un intervalo de más o menos tres semanas, los días Jueves en la tarde, y el método de trabajo que se acordó fue inicialmente de repartir encuestas sobre un tema determinado, con la suficiente antelación, que los interesados contestaban, exponiendo su opinión sobre los puntos consultados con más 
- menos diez días o una semana de anticipación. La Secretaría, con el esfuerzo de Hernández y de Francisco Maldonado y de Fernando Londoño, que colabora con él, se encargó de sintetizar éstos y repartirlos oportunamente, para que cuando llegara la sesión en que el tema se debatía, cada uno ya supiera las opiniones de los otros, lo que se había opinado sobre eso, y la discusión fuera por supuesto mucho más fructífera que si recién en ese momento empezaran a confrontarse los pareceres. El sistema dio excelente resultado, y nos permitió avanzar con muchísima mayor eficiencia que si se hubiera simplemente lanzado un tema al debate para escuchar con mayor o menor orden o desorden las opiniones y para, no diré sorpresa, porque en realidad la crítica más generalizada ya se dejaba sentir en ese aspecto, el orden en que el Foro se propuso examinar los distintos aspectos del Código fue empezar por Parte General y luego por Parte Especial -lo que es muy lógico-, pero en la Parte General comenzar por la Penas, no por los elementos del delito, los agentes del delito, las circunstancias eximentes, atenuantes, agravantes, etc. sino por el sistema de penas, porque nos pareció que un Código inspirado en buenos principios, como es el nuestro, en esa parte fallaba.

Desde luego, la preferencia extraordinaria concedida a las penas privativas de libertad, en seguida la variedad muy grande de penas, que en principio no es un defecto y sería deseable, pero que en la práctica no se aplicaban, y después por el sistema que por suerte nuestro Código no llevó a extremos, como sucedió en otras partes, pero que evidenciaba el espíritu de la época pensando que la ley era clara, completa y coherente, ella misma determinaba qué pena debía aplicarse y dejaba muy poco margen al criterio judicial y la apreciación de cada caso en concreto. Estableció además ese sistema de las escalas y de los peldaños, que se bajan y se suben, según determinados criterios que ustedes todos conocen, de las circunstancias atenuantes o agravantes, del grado de participación, del de desarrollo del delito, etc.

Este es el orden que el Foro se propuso para el examen del Código, y el calendario temático, para que ustedes vean en qué medida se ha avanzado en esto, dice así:

Primero, Parte General. Pena: sistemas de penas; penas privativas de libertad y sustitutivos; sistema de penas; penas alternativas a la privación de libertad; determinación legal de la pena; criterios de individualización (o sea de determinación judicial de la pena); circunstancias modificadoras de responsabilidad penal; el problema del control de ejecución de las penas (en que ha habido un consenso muy grande a mi parecer en la necesidad de crear una jurisdicción especial para la ejecución y cumplimiento de las penas) y, lo que figura al final, pero que es lo único que va a darle solidez y permanencia al nuevo sistema, la problemática del respaldo constitucional para el régimen de penas. 
Después, la Parte General y los temas que habitualmente ahí se estudian: acción y omisión; dolo y culpa; error; causa de justificación; inimputabilidad; inexigibilidad de otra conducta; etc. pero ése es el orden.

Comenzamos en el Foro por formular una profesión de fe, recordando lo que se había hecho al empezar el Proyecto de Código Penal Tipo, que no es ni siquiera en carácter de proposición, textos legislativos o textos destinados a convertirse en leyes, sino las bases sobre las cuales no había disenso, sino que toda la asamblea estaba conteste en que esos deberían ser los principios inspiradores.

Después de varias correcciones, la versión definitiva de los principios orientadores dice así:

1) "La proliferación excesiva de tipos penales es desaconsejable porque erosiona, tanto las condiciones de legitimidad como de efectividad del derecho penal. El legislador debe limitarse a incriminar hechos perjudiciales especialmente graves y socialmente intolerables. Debe evitarse recurrir a la ley penal si hay medios disponibles de otra naturaleza menos gravosa y aptos para hacer frente a las conductas prohibidas".

2) "Sólo la ley puede imponer una sanción penal debiendo describir claramente las conductas a las que deba aplicarse y sin que nunca pueda extenderse por analogía a hechos que no reúnan todos los requisitos legales previstos para su castigo. Se permite sin embargo, la analogía que favorece al imputado".

3) "Las sanciones penales sólo se aplicarán a hechos ocurridos con posterioridad a su promulgación, salvo que sus disposiciones redunden en un tratamiento más favorable para el hechor por supresión o mitigación de la sanción. El hechor será oído en lo que respecta a la apreciación de la ley que le sea más favorable, sin que su opinión deba seguirse obligatoriamente por el tribunal".

4) "Los delitos cometidos por menores deben ser regulados por un estatuto jurídico diferente del aplicable a los adultos, que en todo caso, debe considerar al menos las mismas garantías y derechos que rigen para éstos. Tanto el catálogo de conductas punibles como las sanciones aplicables deben ser proporcionalmente menos gravosos que los vigentes para los adultos".

5) "De establecer un sistema de medidas de seguridad o corrección, no podrán aplicarse tales medidas, sino a quienes sean incapaces de conforman su conducta a la norma, y sólo en cuanto hayan incurrido previamente en un hecho ilícito en condiciones en que a cualquier persona hubiese sido exigible evitarlo. Se suprime por lo tanto la peligrosidad sin delito. No podrá aplicarse al mismo tiempo y por un mismo hecho, una pena y una medida de seguridad o corrección. La aplicación de la medida de seguridad 
y protección debe estar sujeta a garantías y controles equivalentes a los vigentes para las penas".

6) "No podrá imponerse pena por pensamientos, intenciones, opiniones o estados, características o circunstancias de las personas, sino sólo por conductas perjudiciales graves y socialmente intolerables".

7) "Asimismo, no podrá imponerse pena por conductas realizadas en privado que no afecten a terceros".

8) "No podrá imponerse pena sino a aquéllos que hayan realizado los hechos tipificados por la ley como delitos, con intención, aceptación, previsión o al menos imprudencia o negligencia. Al momento de establecer las penas aplicables al hecho, la ley debe distinguir la distinta gravedad de las situaciones en que a su respecto puede encontrarse el hechor".

9) "Tampoco podrá imponerse pena, cuando quien ha realizado la conducta delictiva lo ha hecho privado de libertad interna de decisión, por encontrarse en grave riesgo, en extrema necesidad, en situación de error invencible de cualquiera naturaleza o en otras circunstancias semejantes".

10) "La ley deberá prever un rango de magnitud adecuado u opciones penales alternativas para que el tribunal que debe imponer sanción pueda aplicar en naturaleza, duración o monto, la más apropiada para cada caso".

11) "No podrán establecerse penas ni medidas de seguridad o corrección, que tengan carácter cruel, inhumano o degradante".

12) "Quedan prohibidas las penas de muerte, las tortura, mutilación, marcación, y todas aquellas que hubieren de aplicarse compulsivamente en el cuerpo de la persona".

13) "Quedan igualmente prohibidas las penas perpetuas, y respecto de las temporales su duración máxima no debe extenderse a un período que importe privar al condenado de la posibilidad efectiva de reinserción social".

14) "En cuanto a las penas pecunarias, quedan prohibidas aquellas que por su monto resulten confiscatorias en relación con el patrimonio del sancionado. La ley debe establecer un sistema que impida que la aplicación de las penas pecunarias produzca efectos discriminatorios entre los más ricos y los más pobres".

15) "La aplicación de penas de encierro, debe respetar la dignidad humana. Por consiguiente, sólo pueden propender a la educación o tratamiento del condenado 
cuando éste, libre y voluntariamente, consienta en ello. Deberán ser controladas y revisadas periódicamente por parte de una instancia judicial".

16) "Deberá evitarse, tanto la amenaza abstracta de penas privativas de libertad de corta duración, procediéndose a la supresión o adecuación de los tipos penales que exclusivamente contemplan ese tipo de penas, como la imposición de penas de estas características en los casos concretos. En estos casos se deben aplicar penas alternativas que no signifiquen encierro".

17) "El estado deberá crear establecimientos, instituciones o mecanismos, o en su caso, adecuar los ya existentes, para hacer posible el cumplimiento de penas consistentes en desarrollar trabajos en beneficio de la comunidad, y proveer un adecuado sistema de vigilancia para quienes han recibido penas que los obligan a permanecer en determinado lugar del territorio nacional, o a no presentarse en otros, o a cumplir penas en reclusión domiciliaria".

Esos son los principios compartidos por la unanimidad de los miembros del Foro. Ya verán ustedes que en el desarrollo de los temas, algunos de estos conceptos han sido ligeramente modificados, y en otros han sido concretados o desarrollados más abundantemente.

¿Cuál ha sido hasta ahora el resultado de la discusión en el Foro Penal? Primero, como he dicho, se introdujo el sistema de las encuestas y después llegó un momento en que ya agotada la discusión, pasamos a la consideración de posibles textos concretos que reflejaran los pensamientos emitidos en la comisión y reemplazaran, correspondientemente, los artículos que estuvieren en oposición a ellos dentro del actual Código Penal. Esa tarea está siendo desarrollada en cuanto a redactar los textos concretos, por dos comisiones: una de ellas, de cuyo trabajo precisamente estamos ocupándonos ahora en el debate, presidida por el profesor Jean Pierre Matus, y la otra que espera su turno para establecer el sistema de la determinación concreta de la pena.

No puedo, porque es demasiado extenso y el tiempo no alcanza, leer todas las conclusiones que aquí hay, pero me detendré en algunas que son las más interesantes. Sobre la base de la respuesta a las encuestas, de las exposiciones de los relatores, y especialmente del debate en las respectivas sesiones del Foro, se pueden adelantar las siguientes conclusiones:

\section{Sistemas de Penas}

Primero resulta indispensable la introducción de un sistema jurisdiccional de control de la ejecución penal. No hubo más que una opinión manifestada como respuesta a las encuestas, que, sin oponerse, manifestó cierto escepticismo sobre el 
efecto práctico, beneficioso, que podría producir la creación de esa instancia judicial. En cambio, se hicieron muchas referencias a casos de derecho comparado, en que el sistema había funcionado con bastante éxito.

\section{Inadmisibilidad de la Privación Perpetua de Libertad}

El rechazo se funda en la vulneración de los principios. Las penas perpetuas vulnerarían los principios de humanidad de las penas y de dignidad de las personas, y de la limitación de las penas temporales a la posibilidad de resocialización. Si, respecto de las penas temporales, se sentó como principio que no debieran extenderse más allá del momento en que ya se hace imposible la resocialización del preso, entonces con mayor razón, se justificaba el rechazo a una pena perpetua que la hace definitivamente imposible.

La necesidad y excepcionalidad de las penas temporales privativas de libertad

Este es un punto en el cual yo quiero abreviar estas conclusiones de tipo general, que después van a ser conocidas por todos, para dar alguna opinión, que esta vez ya será una opinión mía, sobre las penas privativas de libertad, sus efectos y su profunda necesidad de reforma. Hubo sí consenso en el Foro, sobre la necesidad de conservar penas privativas de libertad, no de suprimir las prisiones o las penas de encierro, en forma total y definitiva, pero hay una fuerte tendencia a recalcar el carácter excepcional que debe tener la privación de libertad, en términos de ser aplicable sólo respecto de afectaciones graves de los bienes jurídicos más importantes y más relevantes. Sin embargo, no hubo la necesaria concordancia, o no se debatió suficientemente el concretar cuáles serían estos delitos, o cuáles serían estos bienes jurídicos afectados para los cuales se reservarían las penas privativas de libertad. Existió sí unanimidad en orden a suprimir la distinción que actualmente hace nuestro Código entre presidio y reclusión, por estimar que era carente de sentido, y algunos estimaron también que eran reminiscencias de la época de los trabajos forzados.

\section{La duración máxima de las penas privativas de libertad}

Aquí hubo bastante discrepancia en los pareceres. La verdad es que la pregunta que se hizo en la encuesta se refería a la duración de todas las penas temporales, no sólo de las privativas de libertad, pero curiosamente todo el mundo pareció entenderlo en el sentido de que se refería sólo a las penas privativas de libertad, no a las restrictivas o a las privativas de derechos, etc. La mayoría de las respuestas concluyó lo que ustedes han escuchado, es decir, que no debería exceder aquel límite pasado el cual ya la reinserción se hace prácticamente imposible. La dificultad estuvo en cuándo estimaban 
los miembros del Foro que ya la resocialización se hacía imposible. La mayoría estuvo por una pena máxima de 20 años, otros por 15 años (entre los cuales me conté yo), una de las respuestas lo hizo por 25 años, y otra por 30 años, y separada de la escala para los delitos más graves. Aún una opinión solitaria, que estuvo por mantener el presidio perpetuo, estimó que la posibilidad de acceder a la libertad, debía establecerse a los 20 años. Respecto de la duración mínima de las penas privativas de libertad, también pasó lo mismo que con el caso anterior, es decir, todos pensaron en las penas privativas de libertad, no en las de otra naturaleza. Algunos pensaron que no era necesario establecer límite inferior alguno, otros (como fue el caso mío) que debería establecerse una pena mínima privativa de libertad de 3 años, de modo que si el delito fuera merecedor en principio de una pena de presidio más leve, habría que buscar una pena alternativa o sustitutiva.

\section{Las alternativas a la pena privativa de libertad}

Este fue uno de los aspectos más complejos en la discusión del Foro, no respecto del principio mismo, que encontró general aceptación, sino en cómo se podía eso plasmar técnicamente. Hay consenso en cuanto a la necesidad de contar con sanciones alternativas al encierro, e incluso opiniones que pueden considerarse conservadoras en cuanto a mantener ciertas penas, que poco se aplican entre nosotros, restrictivas de derechos, restrictivas de libertad, o privativas de derechos, etc., se fundamenta en que un mayor uso de esa clase de penas podría servir para eliminar la necesidad de aplicar con tan abrumadora mayoría las penas privativas de libertad.

Hubo una discusión interesante en la cual se llegó a una conclusión, más o menos general, sobre si estas penas, debían ser sustitutivas de las de encierro o podían ser penas alternativas a las mismas, esto es, si un delito puede castigarse con pena de encierro o con pena de relegación, o inhabilitación para cargos públicos, etc., situación en la cual las dos tienen carácter de pena principal y son alternativas, y el juez, según regla ya existente en nuestro Código, no está obligado a aplicarle la misma a todos si hay más de un partícipe. Y lo que dio origen a mucha discusión fue también si, en caso de quebrantamiento de esas penas sustitutivas o alternativas, ellas podían transformarse en encierro. El criterio mayoritario fue que la sanción en ese caso debería ser de otra naturaleza, pero no la conversión en pena de encierro, ya que si originalmente se estimaba que el delito por su naturaleza, o por las circunstancias en que se cometió, o por la personalidad del delincuente, no debía ser castigado con presidio, no porque hubiera un quebrantamiento posterior de otra pena cambiaba aquél juicio o criterio original que se había tenido en vista. Se estimó que era necesario definirse en qué delitos NUNCA procedería la aplicación de penas privativas de libertad, y en qué delitos podría imponerse, más o menos dentro de ciertos marcos obligatorios o con las posibilidades de sustentación o alternativa. Esto tiene un carácter 
más bien técnico, creo que no necesito entrar en explicaciones, aunque el debate fue muy largo y muy prolijo, se analizó con derecho comparado y con experiencias recogidas en otras partes.

\section{Alternativas a las penas privativas de libertad}

¿Qué penas en concreto? Aquí la verdad es que el debate no fue tan profundo, porque son instituciones o que serían nuevas en nuestro derecho, o que existen en nuestra ley, pero no se aplican nunca. A favor de ella más bien se alegó que serían preferibles a las penas de encierro o alternativas a las penas de encierro, sin llegar a proponer derechamente un elenco fijo o determinado de penas, que pudieran sustituirse a ella. Se propuso, por ejemplo que los actuales beneficios que concede la ley, como la suspensión, la remisión condicional de la pena, o la libertad vigilada, o la reclusión nocturna, junto con otros como el trabajo de fin de semana, y sobre todo lo que gozó de simpatía muy generales, aún comprendiendo las dificultades de su aplicación práctica, la realización de trabajos de interés general o de beneficio comunitario, que de alguna manera ya están en alguna parte en nuestra ley, pero de las cuales no se hace debida aplicación o debido uso.

\section{Penas pecuniarias}

Unánimemente se considera admisible la existencia de penas pecuniarias y no solo eso, se les considera buenas alternativas a la privación de libertad. Se nota el mantenimiento del sistema que estuvo muy en boga, especialmente en los países escandinavos hace alguna décadas, de los "días multa", pero en realidad y por lo menos esa es mi opinión, el sistema de los días multas puede funcionar eficazmente respecto de aquellas personas "asalariadas", o respecto de quienes por alguna circunstancia puede determinarse con exactitud cuánto es su renta y su ingreso, y corre el riego de que introduzca una discriminación basada en la fortuna o en el dinero, respecto de las personas que tienen grandes fortunas que no son evidentemente aparentes, o desde el punto de vista jurídico atribuibles directamente a ellos, sino a personas jurídicas o entidades que no son la persona misma.

\section{Penas privativas de derechos}

Existe una clara tendencia en orden a ampliar su procedencia; con todo, también se dice que debería regir para ellas el principio de evitar las penas perpetuas y que debería ajustarse a la naturaleza del injusto cometido, o sea, la naturaleza del bien jurídico afectado. Se mencionaron algunas adicionales que ya figuran en el Código, como podrían ser la incapacidad para constituir o ser miembro de determinadas 
personas jurídicas, y la prohibición de desarrollar determinadas actividades económicas o ciertas profesiones, aunque no sean profesionales titulares como las contempladas ahora en el Código. Después, se mencionaron estas otras que ya señalé: el arresto de fin de semana; una interesante, especialmente para las personas enfermas o de mucha edad, como el arresto domiciliario; los trabajos en beneficio de la comunidad; las reclusiones nocturnas; los regímenes de semi-libertad. Incluso, para algunos delitos de muy poca importancia se propuso esta medida que existe respecto de las faltas en el Código de Procedimiento Penal, todavía vigente en el resto del país, que es la amonestación del juez cuando el condenado tiene buenos antecedentes, y es primera vez que delinque, advirtiéndose que una reincidencia o una nueva falta merecería una pena más severa.

Se discutió, más bien técnicamente, la procedencia o la conveniencia de mantener, de suprimir o de aumentar las penas que nuestro Código llama copulativas, alternativas y accesorias. Se llegó a diversas conclusiones. Hubo una mayoría importante por mantener la institución actual de la remisión condicional de la pena, donde influyó mucho en el parecer del Foro el bajo índice de reincidencia cuando se ha sido beneficiario de la remisión, que es inferior al 7\%, lo cual habla bien de la conveniencia de la institución para reemplazo de las penas cortas de prisión. Algunos instaron a que se instituyera esto no como una alternativa a la pena, sino como una pena alternativa en sí misma, sin perjuicio de que en caso de quebrantamiento pudiera dar origen a la imposición de una pena alternativa más grave o incluso de una privativa de libertad. Se estimó deseable un mayor nivel de control, que actualmente en la práctica se limita a ir a firmar con cierta periodicidad, y no existen los recursos ni el personal para tener una mayor vigilancia o control sobre las demás exigencias que se establecen. La reclusión nocturna no encontró tantos adherentes, algunos la consideraron demasiado punitiva y sugirieron su mitigación o bien, derechamente, su reemplazo y otros proponen que se mantenga pero que además se la ponga en el catálogo de "penas" igualmente, no como un beneficio sustitutivo de una pena, que determinados delitos se castiguen con reclusión nocturna derechamente; y la libertad vigilada, se está de acuerdo con su mantención. Se estima que es preferible al régimen carcelario y su tasa de reincidencia, aunque es superior al de la remisión porque llega al $16 \%$ no es tampoco lo suficientemente elevada como para estimarse que es un fracaso y que no ha dado resultado en la práctica.

Finalmente, diremos que sobre la determinación legal por una parte y la judicial, o sea la individualización de la pena, el Foro fue contrario a una determinación legal total. Es decir, fue partidario de que la ley mantuvieran el sistema actual de establecer un cierto marco para cada delito, entre un mínimo y un máximo y se recomendó que se usara un sistema de expresión fácilmente comprensible por el público en general, como la de años o meses, y no los términos más técnicos de grado máximo, mínimo y medio 
de un presidio mayor o menor, etc., que para el que no ha estudiado derecho, no tienen muchas veces una significación muy concreta.

Hubo también una fuerte inclinación por estimar que el juez debía tener una mayor latitud en la consideración de la pena aplicable, limitándola solamente en cuanto a su máximo, pero dejándole bastante liberalidad en cuanto a la consideración de circunstancias que pudieran determinar, o hicieran aconsejable en un caso concreto, penalidades más leves. Como ustedes saben, en materia de control de las penas, el Foro estimó por unanimidad que era conveniente establecer un sistema de vigilancia y de control de la pena tanto para el otorgamiento de beneficios para el condenado, como para evitar abusos por parte de la autoridad administrativa en la ejecución o tratamiento de las sanciones, y del cumplimiento de las penas, y con el asesoramiento técnico necesario para que personas que son en sí mismas juristas, puedan apreciar los aspectos de la personalidad del condenado que hubieren evolucionado favorablemente y lo hicieren acreedor a determinados beneficios.

Como causales que pudieran influir en la mayor o menor determinación de la pena, hubo mayoría en mantener, sin dejar de incluir otros posibles, los criterios de etapas de realización del delito y grados de participación en ellos, que ya contemplan nuestro Código, para poder establecer grados inferiores o superiores de penalidad.

Se estimó también, que era conveniente, a pesar que muchos Códigos modernos no lo hacen así, contemplar, dentro de la Parte General, un catálogo o elenco de circunstancias modificantes de la responsabilidad penal, sea agravante 0 atenuante, sin perjuicio de que, como ocurre también actualmente, respecto de ciertos delitos en particular, pudieran establecer circunstancias acomodadas a su naturaleza.

Y pareció interesante, aunque como se trata de una novedad, no hubo una opinión tan tajante, combinar esta facultad judicial de moverse dentro de marcos más o menos amplios, e incluso modificarlos con ciertos criterios orientadores, pero no cuantitativamente obligatorios fijados por la ley, es decir que la ley dijera que para determinar dentro de los límites que la ley permite la pena efectiva o rebajarla, el tribunal tomará en consideración o se guiará por determinados criterios, entre los cuales estaba una aplicación efectiva del Artículo 69 del Código Penal actual, que en realidad, da pie para que el juez tenga una facultad bastante grande en la graduación de las penas, pero que nuestra práctica judicial es muy reacia a emplearla. Pocas, muy pocas veces, se ven sentencias en que invocando el Artículo 69 se justifica la aplicación de una pena, o más severa o más benigna dentro del marco legal. 
Podríamos sintetizar las conclusiones en la siguiente forma:

\section{Conclusiones sobre el sistema de penas}

a) Es indispensable introducir un sistema de control jurisdiccional de la ejecución penal en Chile, especialmente en materia de penas de encierro;

b) No son aceptables penas de encierro perpetuas;

c) Son aceptables y necesarias las penas temporales de encierro con tal que se apliquen excepcionalmente sólo para los casos más graves;

d) El máximo aceptable para una pena de encierro se encuentra aproximadamente entre los 20 y los 25 años;

e) El instituto de la libertad condicional al término de la pena debe mantenerse;

f) La excepcionalidad de las penas de encierro debe alcanzarse estableciendo ampliamente penas no privativas de libertad, como penas únicas y principales para la mayoría de los simples delitos y no, como hasta ahora, sólo como sustitutivos;

g) Como penas no privativas de libertad por aplicar, deben considerarse en general, más allá de las definiciones de detalles, penas restrictivas de libertad, penas privativas de otros derechos y penas pecuniarias.

Establecer al menos aproximadamente, qué delitos, merecerían la imposición de una pena de encierro, en referencia al bien jurídico y modalidades de afectación, son tareas pendientes para el propio Foro, como también las de definir si en los casos precedentes es posible la sustitución del encierro, mediante qué sustitutos, y en qué medida el sustituto puede convertirse en encierro; definir concretamente el catálogo de penas no privativas de libertad y los caracteres básicos de dichas sanciones; definir los efectos del quebrantamiento de estas penas, concretamente si se pueden convertir o no en penas de encierro; y definir la posibilidad de imponer efectivamente penas cortas de encierro.

En cuanto a la determinación de la pena, las conclusiones son: la ley penal debe establecer marcos penales y no penas completamente determinadas. Al menos el máximo del marco debe estar claramente establecido. Son admisibles causas legales que obligatoriamente impliquen una alteración del marco, como el iter criminis, la participación accesoria, y otras que pudieran definirse. Las circunstancias modificatorias de la responsabilidad penal deben estar en un catálogo ubicado en la 
Parte General del Código, que al menos respecto de las circunstancias agravantes, debe ser taxativo. Sin embargo, a pesar de que hubo un criterio favorable a que se admitieran las atenuantes por analogía, ese no fue un criterio unánime. La individualización judicial debe estar legalmente orientada por criterios y no por prescripciones obligatorias.

Nos quedan muchas definiciones pendientes que se desprenden de la misma exposición que les he hecho, y que ha sido ya excesivamente larga, pero no quisiera terminar sin darles mi opinión personal, sobre todo porque el Foro ha estimado que es imposible suprimir enteramente las penas privativas de libertad, en buenas cuentas, suprimir las prisiones. Yo estoy de acuerdo con ese criterio, pero siempre que las prisiones tengan un carácter absolutamente distinto del que tienen ahora, porque en la actualidad, no cumplen ninguno de los objetivos que teóricamente tiene la pena de encierro y al revés son un factor criminógeno más. El encierro de una persona, suele creerse por las personas que no son juristas o estudiantes de derecho, que consiste simplemente en estar dentro de un recinto más o menos grande o, más o menos chico del cual no se puede salir, pero que esa es la esencia y la limitación de la pena de encierro. Claro, en la ley es así, no se impone ninguna carga adicional: la esencia de esas penas es la privación por un tiempo determinado o por toda la vida de la libertad ambulatoria o de desplazamiento, de ir a donde se quiera ir, pero ustedes saben que la realidad de las prisiones es muy distinta. En las prisiones se crea una sociedad enteramente distinta de la que existe en el exterior, una sociedad que es en primer término autónoma. Se crea una sociedad que funciona, evoluciona, con sus restriciones, con sus conflictos, con sus reglas totalmente diferentes de las que rigen en el exterior. Característica esencial: esa sociedad hace coexistir dos grupos distintos, los gendarmes o guardianes, y los internos o reclusos. Aparentemente, todo los pone en oposición: unos se encargan de controlar, de dar orden, los otros deben someterse, obedecer. La realidad es más compleja que esta simple oposición. Estos dos grupos viven en realidad en simbiosis, en el desarrollo de la vida diaria cada uno depende del otro, la oposición se transforma más bien en dependencia recíproca. En un universo tan limitado toda presión de un grupo ejercido sobre el otro provoca un efecto boomerang y arrastra una cadena de consecuencias en que todos están implicados. Un pequeño incidente que en una sociedad abierta sería insignificante puede transformarse en una catástrofe en el estrecho mundo de la prisión. Muchos de estos grandes amotinamientos que ustedes han vistos, con consecuencias tan trágicas y tan terribles, han tenido su origen en incidentes absolutamente insignificantes, que en una sociedad exterior, abierta no habrían tenido alcance ninguno, salvo tal vez alguna simple riña sin mayores consecuencias.

La carrera de los gendarmes, sus calificaciones, sus ascensos, por lo tanto sus sueldos, dependen del buen funcionamiento del establecimiento, o sea de la observancia 
de las reglas por los presos. Los presos lo saben, y tienen conciencia de que por ese hecho detentan también un cierto poder. En compensación por su colaboración a una vida sin incidentes, obtienen ciertos tolerancias, se implanta un régimen de intercambio recíproco de buenos procedimientos y de buenos comportamientos, se hacen posibles las pequeñas y a veces no tan pequeñas excepciones a la letra del reglamento, la colaboración se transforma en connivencia y pasado cierto tiempo la connivencia en complicidad. La vista gorda abre las puertas a la corrupción. Por la misma razón de sus límites y de su encierro, la sociedad carcelaria engendra la inestabilidad de todos los que participan en ella.

¿Es posible reducir las penas de prisión? Yo creo que sí, y esto nos lleva al punto final. Simplemente algunas reflexiones sobre cómo resolver el problema del atochamiento de las cárceles. Porque si hay celdas construidas para albergar a una persona, o a dos personas, y en ellas se albergan tres o cuatros personas, entonces no se está solamente condenado al encierro consistente en privación de libertad ambulatoria, sino además a vivir en un régimen de promiscuidad, antihigiénica y repugnante en muchos casos. No quiero siquiera referirme a los problemas producidos por el estado de salud, el contagio de los presos, el desarrollo del Sida en los últimos tiempos. ¿Qué podría hacerse por eso? Primero, restringir como en el Foro se ha visto, la tendencia a las penas de encierro realmente sólo a los crímenes de mayor gravedad, que no representan, en Chile al menos, más allá de un 7 o un $8 \%$ de las condenas por homicidios, violaciones, robos con intimidación, etc. Suprimirla como la "gran medida" para el delito contra la propiedad de pequeña entidad o que afecta a otros bienes jurídicos no tan importantes; segundo, y gran culpable del atochamiento de las cárceles en Chile, es la prolongación excesiva de la prisión preventiva. Si la prisión preventiva se prolonga excesivamente, atenta contra su propia naturaleza, contra la presunción de inocencia como ustedes lo saben. Yo comprendo que en algunos casos sea necesaria la prisión preventiva para aquellos que muy taxativamente señala la propia Constitución Política, pero, diría yo entonces, la persona a la cual se le niega la libertad provisional y debe estar en prisión preventiva, tiene derecho a ser juzgada expeditamente y a que el juicio definitivo sobre su suerte se decida en un plazo perentorio e improrrogable. Eso produciría una descongestión enorme en las cárceles, porque en la actualidad, aproximadamente la mitad de los que están en reclusión en Chile son personas que esperan juicio, no son personas condenadas.

La medida más audaz, más decisiva, pero creo que nuestro país no está maduro todavía para aceptarla, es la adoptada en Holanda del numerus clausus, es decir, si una prisión está llena y se produce una condena a prisión, para que entre el nuevo condenado debe salir un condenado antiguo, aquel al que le falte menos tiempo para salir, o que otros sistemas de calificación interna en cuanto a su conducta etc. indiquen que esté en mejores condiciones para salir al exterior. Esa medida se aplica actualmente en Holanda. Creo que, desgraciadamente, nuestra sociedad no está preparada para ella 
pero quién sabe, podría hacerse alguna campaña de opinión a favor de esa solución. Lo que no me parece que sea una solución es el de las cárceles privadas o concesionadas, porque realmente aun cuando se retuviera, como es lógico, para el Estado el mantenimiento del orden interno, la gendarmería, la aplicación del reglamento carcelario etc. pero, que se contratara con una empresa exterior tanto la construcción del edificio como ciertos servicios de aseo, de alimentación de los internos etc. toda esa empresa está hecha con fines de lucro, y es lógico, no se le puede reprochar al particular que se presenta para la concesión de una cárcel que pretenda obtener fines de lucro. Entonces, ¿qué sucede?: que a la empresa que contrata y al Estado, les conviene un aumento de la delincuencia, que las cárceles estén siempre llenas, porque una celda vacía es de menos utilidad para el concesionario, y en vez de procurarse la disminución de la delincuencia y de las penas de encierro, este sistema provoca por el contrario, y aunque sea desde el punto de vista psicológico y de la moral social, el deseo de que la delincuencia no disminuya.

En fin, quisiera terminar con una cita de un maestro que todos ustedes conocen, que es CARNELUTTI, en su obra sobre "Las miserias del proceso penal", el cual dice textualmente: "... el proceso penal termina con la sentencia, pero si es condenatoria se prolonga con la pena, y cumplida la pena, se prolonga con la actitud de la sociedad. El preso al salir de la prisión cree no ser ya un preso, pero la gente no. Para la gente él es siempre un preso, a lo más se dice un ex-preso, un ex-carcelado, en esta fórmula están la crueldad y el engaño. La sociedad clava a uno en su pasado: éste ha robado, lo han condenado, ha cumplido íntegramente su pena, o como se dice con esa frase tan comúnmente empleada: "ha pagado su deuda con la sociedad pero...", y en ese "pero" están la crueldad y el engaño", "pero podría robar de nuevo, por lo tanto yo no le doy trabajo". Así razona la gente, cree que cada uno seguirá siendo como ha sido, y no la gente vulgar solamente, sino también los hombres de gran cultura e incluso aquellos que hacen profesión de cristianismo. Nadie quiere correr el necesario riesgo de la caridad y la generosidad. Así el ex-ladrón queda sin trabajo, llama a esta puerta, llama a esta otra, son todas personas razonables que podrian permitirle ganarse el pan de un modo honesto, pero estas personas razonables quieren tener garantías. Para su garantía ¿no se ha inventado el certificado de antecedentes? Entonces "a ver... examinemos su certificado". El ex-ladrón está así marcado en la frente. Pocos días bastan para terminarle todas las ilusiones que se hacía en la prisión para el momento de liberación, y llega a pensar que después de todo estaba mejor en la cárcel. Y el Estado que debería remediar esta situación es el más exigente de todos, porque entre nosotros está permitido, como ustedes saben, que en ciertos casos y cumplidas determinadas obligaciones se otorguen certificados de antecedentes en que se omitan ciertas condenas que no son por los delitos más graves $y$, respecto de los cuales haya pasado algún tiempo, precisamente para permitir que la gente encuentre trabajo. Pero eso no 
rige cuando lo que se busca es un empleo del Estado: en ese caso no se puede omitir del certificado ningún antecedente, por antiguo o leve que sea.

"Conclusión, la gente cree que el proceso penal termina con la condena y no es verdad, la gente cree que la pena termina con la salida de la cárcel y no es verdad, la gente cree que el presidio perpetuo es la única pena que dura toda la vida y no es verdad, la pena no termina nunca, quien ha delinquido una vez está perdido. Dios perdona setenta veces siete, pero la sociedad no".

Gracias. 